\title{
Editorial
}

\section{Comments on Bilateral Neonatal Testicular Torsion}

David A. Bloom, MD

Harry P. Koo, MD

\section{Introduction}

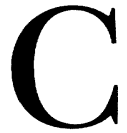

ooper, Snyder, and Hawtrey offer an important observation and valuable lesson for all who take care of children in their paper, Bilateral neonatal testicular torsion. The gonads are prime examples of the genetic wisdom with which $\mathrm{Na}$ ture has added redundancy to most critical systems. The main threats to human testes are trauma and torsion. Education of health care workers as well as families can mitigate these threats.

Neonatal testicular torsion is an extraordinary phenomenon. For many years after the first report of testicular torsion, in 1840 when Delasiauve described a case in a cryptorchid testis, the cause and treatment were poorly understood. ${ }^{1}$ Today, a number of mysteries regarding pathogenesis and presentation remain, but the treatment is plain and clear: twisted testes should be untwisted before they die. The comprehensive review by Das and Singer ${ }^{2}$ found that $72 \%$ of perinatal torsions occur prenatally and $28 \%$ occur postnatally. Whether the socalled vanished testis is due to these conditions or to some other prenatal vascular accident is yet unknown, but whatever the cause, it is a fact that most vanished testes are on the left side. Yet, perinatal torsion seems to have equivalent prevalence on either side. Curiously, neonatal torsions, even the postnatal variants, are asymptomatic. In contrast, torsion later in childhood is exquisitely symptomatic. We have no explanation for this. Does the brain rewire its pain pathways after infancy or is there something unique about neonatal torsion that renders it painless? The neonatal twist occurs along the spermatic cord above the insertion of the tunica vaginalis (the sacs that surround the testis). Neonatal torsion is therefore described as extravaginal torsion, whereas the more common testicular torsion of childhood or young adults occurs within the tunica vaginalis and is termed intravaginal torsion.

Neonatal torsion is usually unilateral, but it may occur bilaterally. We have personally seen synchronous as well as metachronous bilateral torsions. The case presented herein by Cooper, Snyder, and Hawtrey is doubly tragic in that it not only was bilateral,

Clin Pediatr. 1997;36:657-658

University of Michigan, Ann Arbor, MI.

Reprint requests and correspondence to: David A. Bloom, MD, Chief Pediatric Urology, University of Michigan, 1500 E. Medical Center Drive, Ann Arbor, MI 48109-0330.

(C) 1997 Westminster Publications, Inc., 708 Glen Cove Avenue, Glen Head, NY 11545, U.S.A.

but it seems to have been postnatal and the testicular loss occurred in spite of sincere medical effort. The good news is that we can improve that effort.

\section{Diagnosis of Torsion}

Making a diagnosis of torsion is not rocket science and does not take much technology. In the neonatal period, the main differential conditions are hydrocele and hernia. Ruling these out, a swollen hemorrhagic hemiscrotum most likely represents unilateral torsion. Bilateral signs should increase the diagnostic anxiety level. Only occasionally must we resort to imaging; if torsion is high on our diagnostic list the next step is to the operating room. ${ }^{3}$

\section{Surgery or Not}

Why operate, particularly in an instance of unilaterality? In our institution, as in most children's hospitals, we have the luxury of first-rate pediatric anesthesia. We do not enter the operating room lightly, but we are convinced that the pediatric anesthetic risk in our environment is less than that of an automobile ride; in more than a dozen years at the Mott Children's Hospital, we have not lost one patient to pediatric anesthesia and surgery, but we have lost several children to vehicular accidents. 
Surgical exploration permits the definitive diagnosis of torsion. Salvage of the prenatal variant is unlikely; the duration of torsion most likely exceeds the interval of reversible ischemia, which seems to be in the range of 6 hours. ${ }^{4}$ Postnatal salvage is possible, although rare in the literature. The 6-hour barrier has been difficult to break in neonatal torsion, although, ironically, most of these infants are hospitalized in that time frame.

\section{The Contralateral Testis}

In our opinion, the most important aspect of a prompt operative approach is that it affords an opportunity to secure a contralateral untwisted testis. This is a controversial point. The contralateral testis may not have a "higher than normal" likelihood of metachronous torsion, but in the words of Harris et al, the loss of a solitary testis is a "catastrophe beyond measure." A few sutures, placed without compromise of testicular parenchyma or ductal structures, can minimize the chance of such catastrophe. We operated on one boy for an apparent unilateral neonatal torsion, and after the large soft necrotic gonad was removed, we approached the contralateral gonad finding it to be little more than a firm old organized necrotic mass. This was an instance of metachronous bilaterality, but initially we had recognized only the most recent torsion and missed the older necrotic gonad. If we had not discovered this operatively, the contralateral atrophy would have been very difficult to explain.

\section{Prostheses}

In our experience, most older boys with a normal solitary testis do not crave bilaterality at the cost of an operation. Many of our colleagues, however, disagree and find that their practices favor placement of unilateral prostheses. Bilateral neonatal torsion, however, results in a small, flat and empty scrotum, which is very obvious in a locker room. For this reason, we think that infantile prostheses serve an important role, even though replacement one time later after puberty with adult size prostheses will be necessary. Up through puberty, there is little change in testicular size, and therefore, only a single size change should be necessary after placement in infancy. We have seen no significant clinical problems with prostheses. Nor have we seen data or reliable anecdote linking any sort of testicular prosthesis with any systemic disorder.

\section{Philosophical Points and Medical Economics}

Surgical solutions to human problems will never disappear; they are usually effective and they usually improve lives. Surgical solutions, although a service, tend to be delivered against the grain of human inclination. Pain, inconvenience, risks, and costs are natural barriers to going under the knife. Parenthood raises even greater barriers to placing one's child in harm's way in an operating room, especially in the absence of immediate risk to life or limb.

The past era of indemnity care removed much of the economic barrier of surgical service. Indeed, incentive was created to provide service, and the dark side of this was that surgical services were sometimes oversold in spite of the natural check and balance of the typical human reluctance to submit to an operative proce- dure. The contemporary managed care paradigm shift reverses the equation and provides disincentives to surgical solutions, or indeed any solution that incurs cost. We will be looking for reasons to withhold operative procedures. It is unlikely we could ever economically justify operation for neonatal torsion, assuming that such a justification could be made ethically. How many eunuchs would be saved by operating on all neonatal torsions? What is the cost of a eunuch (in terms of physician visits, monthly hormone injections, and a set or two of prostheses)? What is the cost of a neonatal exploration? Can algebra give us a meaningful answer in human terms? An even more difficult question is what is the value of a second testis? We should look only to ourselves and our patients for these answers, judging each clinical incident on its own merits and utilizing our most up-to-date armamentarium of knowledge and collegial advice.

\section{REFERENCES}

1. Delasiauve LJ. Descente tardive du testicle gauche, prise pour une hernie étranglée; opération; gangrène du testicule; extirpation de cet organ; accidents divers; guérision. Paris: Béthune \& Plon; (entire book) 1840.

2. Das S, Singer A. Controversies of perinatal torsion of the spermatic cord: a review, survey and recommendations. JUrol. 1990;143:231-233.

3. Bomalaski MD, Bloom DA, Garver KA. Assessment of testicular torsion. In: Topics in Clinical Urology. New Diagnostic Tests. Resnick MI, Spirnak JP, eds. New York and Tokyo: Igaki-Shoin Publishers; 1996:71-87.

4. Donohoe RE, Utley WL. Torsion of the spermatic cord. Urology. 1978; 11:33.

5. Harris $\mathrm{BH}$, Webb HW, Wilkinson $\mathrm{AH}$ Jr, Stevens PS. Protection of the solitary testis. J Pediatr Surg. 1982;17:950952. 